\title{
TRICKLE WATER AND FEEDING SYSTEM IN PLANT CULTURE AND LIGHT-DARK CYCLE EFFECTS ON PLANT GROWTH
}

\author{
T. Takano*. K. Inada**, and J. Takanashi** \\ * Meijo University. Tempaku. Nagoya 468. \\ **National Institute of Agrobiological Resources, Yatabe. Ibaraki 305 Japan
}

\begin{abstract}
Rockwool, as an inert medium covered or bagged with polyethylene film. can be effectively used for plant culture in space station. The most important machine is the pump adjusting the dripping rate in the feeding system. Hydro-aeroponics may be adaptable to a space laboratory. The shortening of the light-dark cycles inhibits plant growth and induces an abnormal morphogenesis. A photoperiod of 12-hr-dark may be needed for plant growth.
\end{abstract}

\section{INTRODUCTION}

in space, we cannot use typical nutrient solution culture systems for plant growth. A new culture system has to be established, e.g. hydro-aeroponics. If the light (I)-dark (d) cycles are 90 minutes $(45(1)+45$ (d)) as in the flight of space shuttle. abnormal plant growth will be induced. It is important to find effective lighting regimes for plant production in a CELSS. Our research was done to establish a method of rockwool culture and lighting regimes for normal plant growth.

\section{TRICKLE WATER AND FEEDING SYSTEM IN PLANT CULTURE}

\section{Methodology}

Rockwool is made from a mixture of basalt and slag as a by-product of the iron industry. Plant seedlings were grown on rockwool media $(7.5 \mathrm{~cm}$ high $\times 10 \mathrm{~cm}$ wide $\times 10 \mathrm{~cm}$ deep). After plant roots were sufficiently distributed in these blocks. seedling blocks were placed on rockwool beds $(7.5 \mathrm{~cm}$ high $\times 25 \mathrm{~cm}$ wide and at least $120 \mathrm{~cm}$ long). Rockwool blocks and beds were then bagged with polyethylene sheets. Water and nutrient solution from fert-irrigator were supplied through spaghetti tube inserted into the rockwool bed (Fig. 1).

\section{$\underline{\text { Results }}$}

Rockwool is 3-4\% solid phase and $96 \%$ fluid phase. Water or solution is dispersed in every direction by capillary attraction among fibers $(10-100 \mu \mathrm{m})$. The total amount of water or nutrient solution to be supplied has to stay within a limitation of $70 \%$ of the water holding capacity. because the bed system has no drainage. The water and feeding system are shown in Fig. 2. When the three way electromagnetic valve (EMV) turns on the water. the piston in the pump adjusting the dripping rate is pressed down. and emits the concentrated nutrient solution as a droplet (0.1-5 ml/stroke). After this work. the water is drained away from pump room and nutrient solution is pumped up. In this case. two stock solutions are prepared in order to prevent precipitate formation. The pump adjusting the dripping rate must be a twin-head proportioner type. As the maximum flow rate of water is 0.5 to 1.0 liter per pulse, the stock solution will be diluted $100-2.000$ times before it finally reaches the plants. This is controlled by a transmitter with a flow meter and a three way EMV via a pump which adjusts the dripping rate. We usually take a 1.000 times dilution of the stock solution to get $40 \mathrm{me} / \mathrm{l}$ total concentration. 50 to $200 \mathrm{ml}$ of nutrient solution or water, depending on plant age is provided to an individual plant, as one dose for a few minutes, repeating four to seven times a day by the use of a timer switch. 


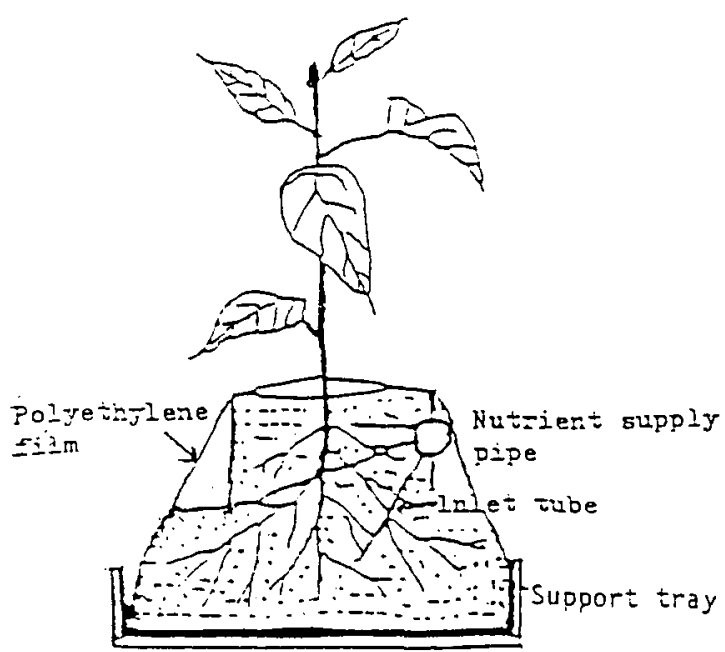

Fig. 1. Plants in rockwool bed with trickle feed lines.

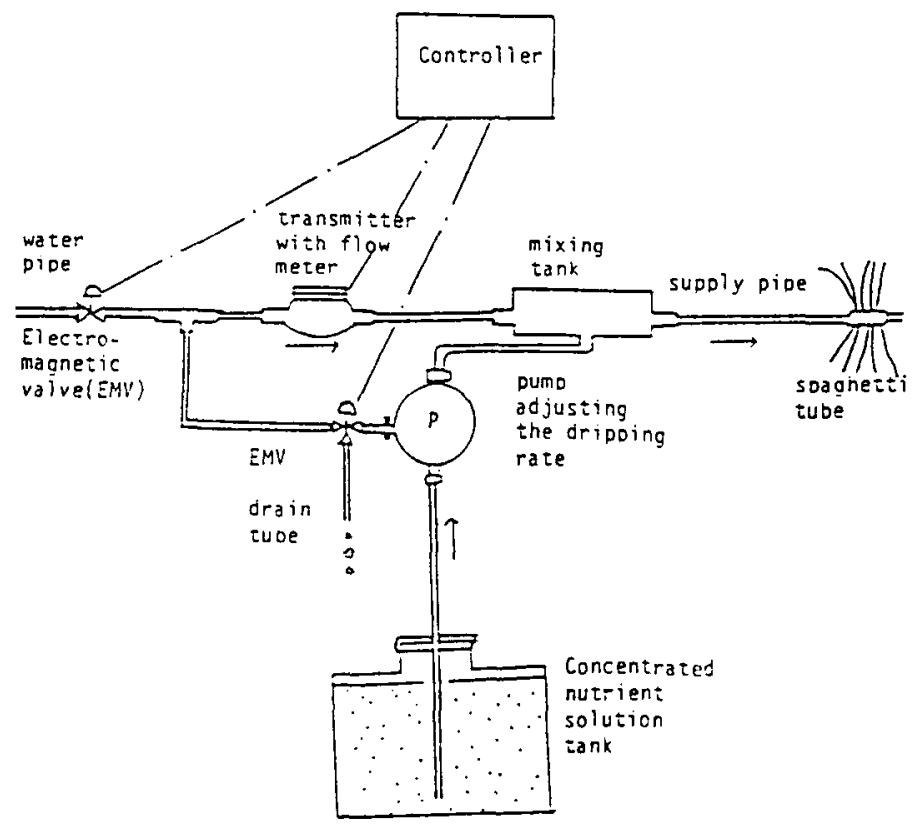

Fig. 2. Main parts of trickle water and feeding system.

Although nutrient composition varies with plant species and its developmental age. the standard ratio of nutrient ions for vegetative growth, i.e. $\mathrm{NO}_{3}-: \mathrm{H}_{2} \mathrm{PO}_{4}: \mathrm{SO}_{4}--: \mathrm{NH}_{4}{ }^{+}: \mathrm{K}+: \mathrm{Ca}^{++}: \mathrm{Mg}^{++}$, is recommended as $23: 7.5$ $: 7.5: 5: 20: 15: 10$. percent of total amount (usually 40 or $20 \mathrm{me} / \mathrm{l}$ ) in chemical equivalents. In reproductive growth stage, $\mathrm{SO}_{4}^{--}$. $\mathrm{Ca}^{++}$. and sometimes $\mathrm{H}_{2} \mathrm{PO}_{4}$ have to be increased, whereas $\mathrm{NO}_{3}^{-} . \mathrm{NH}_{4}{ }^{+}$, and $\mathrm{K}^{+}$ have to be decreased. The minor elements such as Fe. B. Mn. $\mathrm{Zn}$. $\mathrm{Cu}$. and $\mathrm{Mo}$ are also required. In the case of rockwool culture. EDTA chelate of a metal is available for the uptake of nutrients, because of the slightly alkaline solution in rockwool medium. $\mathrm{pH}$ and electroconductivity (EC) should be adjusted automatically at about 6 and below 2 milimhos/cm. respectively /3.4/. Hydro-aeroponics by the use of fert-irrigation system on rockwool medium may be adaptable to a space laboratory, because it does not require the transport of large amounts of heavy, bulky water and rockwool, as a medium, can be used for several crop cycles.

\section{LIGHT-DARK CYCLE EFFECTS ON PLANT GROWTH}

\section{Methodology}

Komatsuna (Brassica campestris L.) and Mung bean (Vigna radiata R. Wilcz.) were grown for 4 and 3 weeks after sowing, respectively. under 24(LD-12). 12(LD-6). 4(LD-2). 1.5(LD-3/4). 0.5(LD-0.25)-hour cycles with 
equal light-dark duration. The light flux rate was adjusted to $175 \mu \mathrm{mol} \mathrm{m} \mathrm{m}^{-2} \mathrm{~s}^{-1}(400-700 \mathrm{~nm})$ or $10.6 \mathrm{klux} \pm$ $6 \%$. Air temperature was kept at $25 \mathrm{C}$ and relative humidity at about $70 \%$.

Results

All growth parameters measured were reduced with shortening the cycles down to LD-3/4, but more or less increased again toward LD-1/4. In LD-3/4 dry weight and leaf area relative to LD-12 were 46 and $55 \%$ in Komatsuna, and $14 \%$ and $15 \%$ in mung bean, respectively (Fig. 3.4).

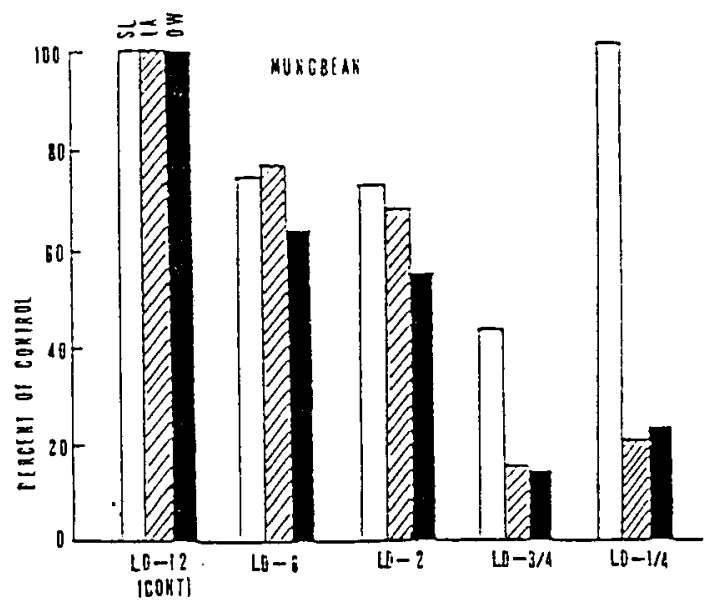

Fig. 3. Growth responses to different regimes of light-dark cycles for three weeks after sowing. SL:vine length. LA:leaf area. DW:dry weight.

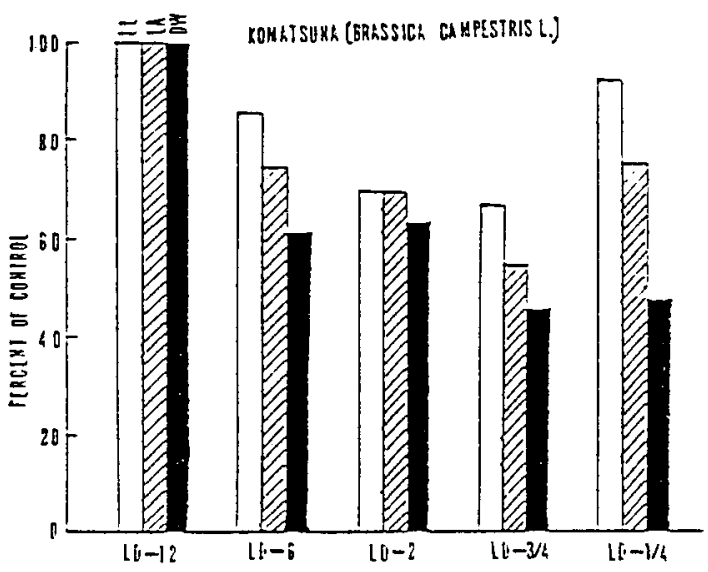

Fig. 4. Growth responses of Komatsuna plants to different regimes of light-dark cycles for 4 weeks after sowing. LL:maximum leaf length. LA:leaf area. DW:dry weight.

Shortening of the cycles gradually decreased the chlorophyll content in leaf blades. whereas it increased the a/b ratio in both species (Table 1). This suggests that reduced photosynthetic activity is caused by a decrease in the total chlorophyll and chlorophyll $b$. With shortening cycles, leaf diffusion resistance increased. whereas the transpiration rate tended to decrease. In 90- and 30-minute cycles, the failure of stomatal function was suggested from the values of diffusion resistance and transpiration rate. These responses also indicate that such short light-dark cycles inhibits the carbon dioxide exchange rate in leaves (Table 2). Conclusively, plant growth in a 90-minute cycle of light-dark period, as in the flight of space shuttle. may be strikingly retarded $/ 2 /$. because of the inhibition of photosynthesis and transpiration. Further studies are needed to find more normal growth under a variety of lighting regimes of longer duration or shorter cyclic period in minutes or seconds /1/. 
Table I. Chlorophyll content ciloropbjll a/b fatio in leaves

as affectod by the lengtbs of a lipt-datr cycle.

\begin{tabular}{|c|c|c|c|c|}
\hline \multirow{2}{*}{$\frac{\text { LiE2: }}{3 \text { efone }}$} & \multicolumn{2}{|c|}{ Munfiean - } & \multicolumn{2}{|c|}{ Xoma:sine $\rightarrow$} \\
\hline & $\left(\begin{array}{ll}\text { Cal } & a+q \\
\left(m_{6}\right. & \left.a^{-2}\right)\end{array}\right.$ & $a / b$ & $\begin{array}{l}C=\sqrt{2+b}) \\
\left(m b a^{-6}\right)\end{array}$ & $a / 0$ \\
\hline $2 I-12$ & $2.20^{\mathrm{a}}$ & $2.46^{a}$ & $3.29^{2}$ & $2.46^{\mathrm{a}}$ \\
\hline $\operatorname{Lim} 6$ & $1.80^{\circ}$ & $2.56^{\mathrm{ab}}$ & $3.03^{2}$ & $2.65^{\circ}$ \\
\hline$L I-2$ & $1.97^{\mathrm{b}}$ & $2.70^{b c}$ & $3.00^{a}$ & $2.77^{\circ}$ \\
\hline $15-3 / 4$ & $2.44^{c}$ & $2.36^{2}$ & $2.54^{b}$ & $2.78^{b}$ \\
\hline $2 \pi-1 / 4$ & $0.75^{\mathrm{d}}$ & $2.87^{c}$ & $1.36^{\circ}$ & $3.07^{\mathrm{c}}$ \\
\hline
\end{tabular}

Note : - dezerzined of 23 rd day after sowion by use of sill-growe leaves. - determinec on 29 in cay atter sowing by use of the lergest leaves.

Different letters on the shoulder of the mean value snow the sicrificest difference for the meltiple range test at the 5-pezcert level.

maile 2. Disfusion resistance and tzanspization gzie of leaves es affected by the leneth of a lifomia-is croles

\begin{tabular}{|c|c|c|c|c|c|c|}
\hline \multirow{2}{*}{$\begin{array}{l}L=E= \\
\text { I0E-100 }\end{array}$} & \multicolumn{2}{|c|}{ In l2eto(d) } & \multicolumn{2}{|c|}{ Is carbess(D) } & \multicolumn{2}{|c|}{$i / D=z=20 \quad 05$} \\
\hline & $\left(s^{D R} \mathrm{cs}^{-1}\right)$ & $\left(\mathrm{TR}_{\mathrm{C}} \mathrm{cs}^{-2} \mathrm{~s}^{-1}\right)$ & $\left(\mathrm{s}^{\mathrm{DR}} \mathrm{G}^{-1}\right)$ & (He $\mathrm{Cs}^{-2}$ & $-1, D R$ & $2 \pi$ \\
\hline \multicolumn{7}{|c|}{ Mus } \\
\hline $25-12$ & $2.74^{2}$ & $5.53^{2}$ & $9.76^{2}$ & $2 . \Delta E^{\mathrm{a}}$ & 0.28 & 3.74 \\
\hline$L=-6$ & $3.16^{2}$ & $5.06^{a}$ & $9.5 i^{\mathrm{ab}}$ & $1.79^{\mathrm{a}}$ & 0.33 & 2.84 \\
\hline$L D-2$ & $4.16^{\mathrm{a}}$ & $3.4 I^{2}$ & $22.46^{b}$ & $0.05^{2}$ & 0.23 & 3.59 \\
\hline$I D-3 / 4$ & $20.92^{b}$ & $2.22^{\mathrm{b}}$ & $10 \cdot 30^{\mathrm{ab}}$ & $2.20^{a}$ & 2.06 & 2.02 \\
\hline $20-1 / 4$ & $12.41^{b}$ & $1.36^{\mathrm{b}}$ & $13.23^{a b}$ & $1.30^{2}$ & 0.86 & 1.06 \\
\hline \multicolumn{7}{|c|}{ KomaIsuna- } \\
\hline$[I-12$ & $I: 14^{a}$ & $10.36^{2 b}$ & $6.94^{2}$ & $2.11^{2}$ & 0.16 & 4.01 \\
\hline 6-6 & $1.12^{2}$ & $9.73^{2}$ & $6.13^{2}$ & $2.82^{2}$ & 0.18 & $j .45$ \\
\hline$L D-2$ & $1.05^{2}$ & $7.88^{b}$ & $2.77^{a b}$ & $3.93^{2 b}$ & 0.38 & 2.01 \\
\hline$[i]-3 / 4$ & $0.99^{2}$ & $6.89^{2 b}$ & $1.65^{b}$ & $6.16^{\circ}$ & 0.61 & 2.44 \\
\hline$L=-1 / 2$ & $2.2 a^{b}$ & $3.7 \varepsilon^{c}$ & $2.3 c^{2}$ & $3.05^{\mathrm{a}}$ & 0.75 & 1.26 \\
\hline
\end{tabular}

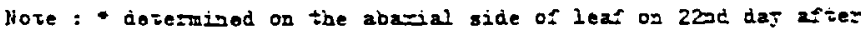
sowing. deterrined on the aberial side of fill-5own leat on 19 th dey arter somine.

\section{REFERENCES}

1.W.W. Garner and H.A. Allard: Effect of abnormally long and short alternation of light and darkness on growth and development of plant. J. Agr. Res. 42:629-651, 1931.

2. K. Inada: Effect of shortening of light-dark cycles on the growth of plants. '85 Japanese CELSS Workshop 101-105. 1985. (In Japanese with English summary).

3. T. Takano: The optimum ratio and amount of nutrients for vegetable crops as determined by the method of systematic variations. Sci. Rept.. Fac. Agr.. Meijo Univ. 14:19-40. 1978.

4. T. Takano: Development of higher plants in the space station environment. CELSS Biol. Res. Rept. 1:9-16. 1984. 